\title{
Vozes mudas, caladas e engasgadas. Afinal, quem tem medo de Megg e do que ela tem a dizer? ${ }^{1}$
}

\author{
RESENHA
}

Michel Alves Ferreira

maferreiragi@gmail.com

Universidade Tecnológica Federal do Paraná (UTFPR), Curitiba,

Paraná, Brasil.

Lindamir Salete Casagrande

lindasc@utfpr.edu.br

Universidade Tecnológica Federal

do Paraná (UTFPR), Curitiba,

Paraná, Brasil
OLIVEIRA, Megg Rayara Gomes de. $\mathbf{O}$ diabo em forma de gente: ( $r$ ) existências de gays afeminados, viados e bichas pretas na educação. Curitiba: Editora Prysmas. 2017. 264p.

\section{PANORAMA GERAL DA AUTORA E OBRA}

Megg Rayara Gomes de Oliveira: pesquisadora brasileira, de origem pobre, negra e com uma (r)existência pessoal marcada por violências e agressões sistemáticas de raça, gênero e condição socioeconômica, é a primeira travesti Doutora da Universidade Federal do Paraná e uma das poucas pesquisadoras que se auto identificam como travestis, transexuais e transgêneros existentes no país, sendo recentemente empossada como docente universitária desta mesma instituição em 17 de maio de 2019, dia internacional de combate à LGBTFOBIA. Sua tese ${ }^{2}$ defendida em março de 2017, intitulada $O$ diabo em forma de gente: $(r)$ existências de gays afeminados, viados e bichas pretas na educação, foi inovadora ao pensar nos corpos de sujeitos considerados periféricos e abjetos para a lógica heteronormativa, branca e masculina, corpos estes de ( $r$ ) existência no campo da educação. A tese, inclusive, concorreu em 2018 ao prêmio de melhores teses e dissertações produzidas nos cursos de pós-graduação brasileiros, prêmio este concedido pela Capes/MEC. Cabe ressaltar que a tese se vale de uma linguagem pouco usual para documentos acadêmicos. Foi desta tese que o livro, resenhado a quatro mãos ${ }^{3}$, surgiu.

Quatro foram as histórias que, somadas à sua própria, se tornaram substrato metodológico da tese que originou o livro, estes de natureza autobiográfica. Utilizou-se o método de história de vida e as entrevistas foram elementos que operacionalizaram o método proposto.

A obra de Oliveira (2017) obriga a reconhecer que as escolas e as universidades, que deveriam ser espaços de acolhimento e de desenvolvimento integral do ser humano, podem se constituir em local de dor, sofrimento e exclusão para as pessoas que não se enquadram ao padrão social e culturalmente construído como desejável. Também leva a refletir sobre as práticas docentes e discentes em relação a essas pessoas que, embora tenham direito a formação escolar e 
acadêmica, ao respeito como ser humanos que são e direito a vida, são, muitas vezes, expulsas do meio estudantil e, por consequência, jogadas à marginalidade.

Os resultados da pesquisa apontaram para a estigmatização de corpos abjetos nos campos da educação ao mesmo tempo em que são elementos de existência e resistências diárias, em razão de sua presença nestes espaços de poder e de formação educacional, especialmente se são docentes que ressignificam as várias agressões sofridas em sua trajetória.

\section{CARACTERÍSTICAS/CATEGORIAS CENTRAIS}

Oliveira (2017, p. 57-58), explicita seu problema de pesquisa do seguinte modo: "[...] identificar os elementos que incidem de maneira positiva nos processos de subjetivação das experiências negras que fogem à norma cis heterossexual e como esses elementos são agenciados no interior da escola".

Embora os objetivos não estejam explicitados, tanto na tese quanto no livro, de modo tradicional, para Oliveira (2017) é evidente que o objetivo central da pesquisa concerne perfazer uma análise situada e crítica acerca das existências e resistências ${ }^{4}$ de sujeitos considerados abjetos nos espaços da escola. Sujeitos estes que são sistematicamente levados a se evadirem da escola. Aliás, outro mérito da obra remete ao fato de problematizar o conceito de evasão escolar: para a autora, como se pode falar em evasão quando os sujeitos são sistematicamente perseguidos e violentados em espaços de uma instituição que deveria ser plural, mas, que em suas práticas/relações corrobora para normalizar e normatizar os padrões de sujeitos ideais a uma sociedade? Para que segmentos da sociedade? Oliveira (2017) deixa claro em seu livro que o correto seria reconhecer que há aí uma expulsão desses sujeitos abjetos pela escola, enquanto instituição normalizadora/normatizadora.

Destarte, a autora (2017) parte de um conjunto de tessituras teóricas, combinadas com depoimentos de quatro docentes autodeclarados homossexuais e negros, todos da rede de educação básica dos estados do Paraná e Rio de Janeiro, aliados ao seu próprio testemunho de vida, para sustentar a ideia de que as escolas a todo instante tentam expurgar estes sujeitos de seus espaços. Se não consegue, a escola desenvolve um conjunto de dispositivos para produzir corpos dóceis e não questionadores à cisheteronormatividade masculina e branca, ainda que impute sofrimentos sistemáticos a estes sujeitos. Oliveira (2017) entende que o conceito de interseccionalidade, conforme Kimberlé Creenshaw ${ }^{5}$, é fundamental para pensar em questões de raça, gênero e classe social de pessoas negras, sendo este um dos conceitos chave da obra.

As categorias viado, bicha, preta, gay e negro, de acordo com Oliveira (2017), não foram apenas utilizados como adjetivos, mas sim transformados em elementos de análise e discussão, uma vez que as pessoas entrevistadas se valiam destes termos para afirmar e reafirmar suas existências no campo da educação.

Neste livro, Oliveira (2017) evidencia situações específicas de si mesma e de seus entrevistados, ao se apropriaram destas categorias mencionadas acima que a sociedade brasileira usa para depreciá-los a todo instante. A apropriação positiva destas categorias não só se evidencia claramente que estas pessoas existem no país, mas que principalmente devem ser respeitadas. De tal modo que, ao adentrar 
no espaço estudantil com sua negritude e sexualidade assumidas orgulhosamente, estas pessoas oferecem uma possibilidade de existências e resistências contra as violências sofridas no ambiente escolar, de acordo com Oliveira (2017).

A autora fez uma extensa pesquisa bibliográfica/historiográfica, acerca de questões raciais e de estigmatização destes sujeitos. Para Oliveira (2017), há aqui um acerto de contas com o passado, a partir do momento em que estes sujeitos estigmatizados retornam à escola como docentes. Ao mesmo tempo em que dão um outro sentido à sua própria história, obrigam a escola, enquanto instituição, sistema e corpo pedagógico/docente, a repensar suas práticas/dispositivos de controle dos corpos/sujeitos. Além de trazer um alento a tantas outras bichas, pretas, viadas e travestis que querem dar um outro sentido às suas vidas a partir da educação, evitando serem simplesmente deixadas à margem de uma sociedade, ainda marcadamente colonialista, racista, misógina e homofóbica.

Do mesmo modo ao trazer logo no início, tanto em seu livro quanto em sua tese, a contextualização histórico/social, artística e religiosa da figura do diabo, Oliveira (2017) problematiza como sujeitos considerados diabólicos por diferentes segmentos das instituições (incluindo aí a escola) não só evidenciam os estigmas imputados a si, mas ressignificam estes em favor de uma valorização integral da dignidade da pessoa humana. Desmontam-se aqui as ideias/fundamentos de um conhecimento neutro, imparcial e universal, inclusive pelos aparatos científicos/tecnológicos que os representam.

É importante ressaltar que se destacam na obra de Oliveira (2017) as correntes pós-estruturalistas, notadamente, as epistemologias feministas e raciais a partir de um ponto de vista, onde o conceito de interseccionalidade de Creenshaw se encontra devidamente localizado.

A autora finaliza seu livro afirmando que a ocupação de espaços de poder pelos sujeitos periféricos à determinados grupos sociais, é necessária para desmascarar os dispositivos misóginos, homofóbicos e racistas existentes nas práticas de ensino e aprendizagem, bem como em todos os demais espaços da sociedade. Ocupar estes espaços significa também, de acordo com a pesquisadora, ser voz ressoante para muitos sujeitos oprimidos nestes ambientes, ressignificando sua própria história e a produção/consumo de saberes.

Sem dúvidas, o livro $O$ diabo em forma de gente: (r)existências de gays afeminados, viados e bichas pretas na educação é uma obra que deve ser lida, discutida e problematizada, de maneira que os espaços escolares ressignifiquem o medo do que Megg tem a dizer.

\section{NOTAS}

${ }^{1} \mathrm{O}$ título escolhido para esta breve resenha faz alusão ao poema Vozes-Mulheres, da escritora brasileira premiada em 2015 com o Prêmio Jabuti de Literatura, uma das mais significativas honrarias concedidas a escritoras e escritores brasileiros: Maria da Conceição Evaristo Brito. Ao narrar as trajetórias de vida de mulheres negras de uma família, marcadas por diversos existires e reexistires em uma sociedade marcadamente desigual e violenta à população negra, Conceição Evaristo (como é conhecida) resgata a ancestralidade, a coletividade e o eco destas vozes para um presente e um futuro dignos, tal como os relatos apresentados no livro e 
na tese de Megg. Também, ao fazer a provocação no título, de quem tem medo de Megg e do que ela tem a dizer, pretende-se problematizar os estigmas imputados à figura do mal, tal como o Lobo Mau eternizado na tv pelos estúdios Disney; tal como Megg perfaz ao criticar a associação moral, cultural, religiosa e cristã da figura do diabo com a população negra. Referência completa do livro de Conceição Evaristo, onde se pode encontrar este poema mencionado no título desta resenha: EVARISTO, Conceição. Poemas da recordação e outros movimentos. Belo Horizonte: Nandyala, 2008.

${ }^{2}$ OLIVEIRA, Megg Rayara Gomes de. 0 diabo em forma de gente: ( $r$ ) existências de gays afeminados, viados e bichas pretas na educação. 2017. 190f. Tese (Doutorado em Educação) - Programa de Pós-Graduação em Educação. Universidade Federal do Paraná. Curitiba, 2017.

${ }^{3}$ Resenha elaborada por Michel Alves Ferreira, pesquisador paulistano/paranaense negro, gay e com uma história de inúmeros marcadores interseccionais em sua $(r)$ existência. Também elaborou esta resenha Lindamir Salete Casagrande, pesquisadora paranaense feminista, do interior do paraná, de origem pobre e com uma vida onde teve de lutar muito para conseguir ser ouvida, vista e respeitada. Não só acreditamos em interseccionalidade como uma epistemologia fundamental para combater as diferentes violações a grupos sociais marcadamente estigmatizados, especialmente no que diz respeito à população negra e às mulheres negras. Mas também cremos que uma produção do conhecimento científico é situacional, localizada, marcada, não neutra e parcial. Então, nós nos posicionamos para visibilizar tantas pessoas que produzem/criticam conhecimento neste país, em lugares onde supostamente não estão ou não deveriam estar, tal como Megg.

${ }^{4}$ FOUCAULT, Michel. Vigiar e punir. Petrópolis: Vozes, 1975; FOUCAULT, Michel. Microfísica do poder. Rio de Janeiro: Graal, 1979; FOUCAULT, Michel. A história da sexualidade I: a vontade de saber. Rio de Janeiro: Graal, 1999; FOUCAULT, Michel. Em defesa da sociedade: curso no College de France (1975-1976). São Paulo: Martins Fontes, 2005.

${ }^{5}$ CRENSHAW, Kimberle W. A intersecionalidade na discriminação de raça e gênero. In: VV.AA. Cruzamento: raça e gênero. Brasília: Unifem, 2004, p. 7-16.

Recebido: 02/07/2019.

Aprovado: 02/07/2019.

DOI: $10.3895 /$ cgt.v12n40.10312.

Como citar: FERREIRA, Michel Alves; CASAGRANDE, Lindamir Salete. Vozes mudas, caladas e engasgadas. Afinal, quem tem medo de Megg e do que ela tem a dizer? Cad. Gên. Tecnol., Curitiba, v. 12 n. 40, p. 310-313, jul./dez. 2019. Disponível em: https://periodicos.utfpr.edu.br/cgt. Acesso em: XXX.

Correspondência:

Michel Alves Ferreira

Rua Dep. Gabriel Sampaio, 465, Apto. 22, CIC, Curitiba, Paraná, Brasil.

Direito autoral: Este artigo está licenciado sob os termos da Licença Creative Commons-Atribuição 4.0 Internacional. 